\title{
3 The bisexual movement in the Netherlands
}

\author{
Developments and experiences of \\ key bi activists since the 1990s
}

Emiel Maliepaard

\section{Introduction}

In 1993, Eadie argued that bisexual safe spaces or communities are necessary for three interrelated reasons: first, they should be free from oppressive (read: mononormative) regimes and social groups; second, they should be free from fear and anxiety; and third, they should be spaces in which to share similar experiences and set agendas for bisexual activism. Studies from the United Kingdom suggest that bisexual spaces, and by extension bisexual communities, are safe spaces for bisexual people that also provide a sense of belonging and a feeling of home (Bowes-Catton, Barker, \& Richards, 2011; Voss, Browne, \& Gupta, 2014).

While demarcated gay and lesbian spaces exist - for instance, bars, clubs, saunas, and gay and lesbian community organisations - it has been argued that no such spaces exist for bisexual people (Hemmings, 2002; see also Maliepaard, 2020). In the absence of structural and demarcated bisexual spaces, activities organised by bisexual organisations can be understood as temporary "homes" for bisexual people (Bowes-Catton et al., 2011), or even as "bitopias" (Formby, 2017). It has been suggested that temporary events such as the BiCon bisexual conference, a multiday event consisting of workshops, seminars, panel discussions, and parties, and BiFest, a one-day bisexual festival comprising workshops, seminars, and a final party, are the bisexual equivalent of structural and demarcated meeting spaces for gay men and lesbians (Voss, Browne, \& Gupta, 2014).

A Dutch qualitative study $(\mathrm{n}=31)$ concluded that most bisexual participants were unaware of national bisexual organisations in the Netherlands: not one participant mentioned a local bisexual group (Maliepaard, 2017). Nevertheless, the Netherlands has a history of bisexual activism, including organisations such as Stichting Bisexualiteit Nederland (Dutch Bisexuality Foundation) and Landelijk Netwerk Biseksualiteit (LNBi, or Dutch Bisexual Network). While the former was dissolved many years ago, the latter merged with other LGBT+ organisations only in 2019, after being there for bisexual and other plurisexual people in the Netherlands for more than 25 years. 
Furthermore, in the 1990s and early 2000s, various local organisations existed that organised support groups, social groups, and activities for bisexual people, particularly in major Dutch cities such as Amsterdam, The Hague, Rotterdam, Utrecht, and Nijmegen, but also in various smaller cities and regions. By 2019, however, only four organisations - in Amsterdam, Nijmegen, Arnhem, and the province of South Holland - were organising monthly meetings. Thus, we are witnessing an impoverishment of the bisexual landscape in the Netherlands.

This chapter provides a predominantly historical overview of developments in the Dutch bisexual movement on the basis of life history interviews with nine key figures with extensive experience in the movement (Maliepaard, 2019). All the interviewees had contributed to one national bi organisation (the LNBi) in various capacities, and most had also contributed to local organisations for bisexual people.

\section{Bisexual communities?}

Formby (2017) differentiates between four types of LGBT communities: (1) spatial communities; (2) cultural communities; (3) imagined communities; and (4) personal communities. The first category refers to the importance of the geographical proximity of people with certain common characteristics who form a community (Gemeinschaft). Examples are neighbourhoods, villages, or indeed gay ghettos such as the Castro in San Francisco, Kemptown in Brighton, and the Marais in Paris. Cultural communities refer to communities with which people identify through shared meanings and identities. They provide people with a sense of belonging and a feeling of home. There is an "in-group" and an "out-group" - in this case, bisexual and other plurisexual people versus monosexual people. As Formby argues, this type of community may overlap with spatial communities, as interactions between group members are important for creating shared meanings and identities. Imagined communities are based on Anderson's (2006) seminal work on nationalism, where he argues that communities exist in the minds of individuals and not necessarily in personal interactions between community members. Regarding LGBT+ imagined communities, one can argue that the idea that all non-heterosexual people are part of the rainbow family is one example of such a community (e.g. Ferreira, 2014). Finally, personal communities refer to personal networks of like-minded people. This type of community relies on networks of friends and acquaintances, and may function as a support group and at least give members a sense of community. A well-known example is the concept of "families of choice". Formby's typology is used to assess whether the bisexual activists in this study felt that they were part of a bisexual community and, if so, how this community might be described.

Monro (2015) discusses the experiences of organised bisexual communities in the United Kingdom. These communities can be understood 
as created by bisexual people and their allies to provide space to be bisexual, connect with other bisexuals, find refuge from heteronormativity and mononormativity, and set political agendas (see also Van Lisdonk \& Keuzenkamp, 2017). This resembles the need for bisexual spaces pointed out by Eadie (1993), and stresses the function of bisexual communities as safe spaces for visitors/participants. Using Bourdieu's concept of habitus, Monro (2015, p. 95) further argues that a bisexual community could be understood as

a historically grounded set of cultural and social practices (including norms and values) which the individual takes for granted and then, by default, reproduces in interaction with other people and the wider environment.

Well-known practices include the aforementioned BiFest and BiCon, as well as monthly gatherings of local bi organisations. Norms and values mentioned by Monro (2015) include, for example, support for sexually diverse identities and expressions, the importance of consent, anti-commercialism, anti-hierarchism, high levels of emotional expression, and an emphasis on (mutual) care. Monro's conceptualisation of bisexual communities in terms of habitus is used in this study to analyse the activities, political efforts, norms, and values of the Dutch bisexual movement, particularly the LNBi.

\section{Methods}

This study is based on interviews with nine key figures. I defined key people as people who had held board positions in the LNBi for at least five years and/or were recognised within bisexual organisations as icons of bisexual activism. In total, eight of the nine had held board positions; the other participant had not formally occupied a board position, but had volunteered with the LNBi for over a decade. Most participants had also volunteered in local organisations - for instance, as coordinators of local social groups ("circles") for bisexual people.

The participants (all aged 50+) were recruited via purposeful sampling to participate in life history interviews. This research method prioritises the experiences and meaning-making of participants. People think in stories, speak in narratives, and make sense of life via stories (Atkinson, 2002). In life history interviews, the participant is in the lead, and the researcher is mainly there to guide the interview. The interviews lasted between 67 and 113 minutes, averaging around 90 minutes.

The interviews were analysed manually, using a predominantly inductive approach aligned with the principles of the life history interview - that is, prioritising the meaning-making and experiences of the research participants. All interview extracts have been translated by the author; all names are pseudonyms. 


\section{Participating in the Dutch bisexual movement}

Most participants had already participated in the Dutch gay movement before entering the bisexual movement. Sometimes they had done so as visitors to events, but often in more activist and/or organising roles. Most of them had felt comfortable or at ease in the lesbian and gay movement; however, they had not felt at home there. This is an important distinction, and participants mainly attributed the difference to the presence of mononormative assumptions in the gay movement, which made them feel different and sometimes excluded, particularly if they were involved in different-sex relationships. They experienced ignorance and even mistrust from gay and lesbian people. Consequently, the key figures had looked for organisations or events to meet other bisexual people, to share understandings and experiences, and to socialise without worrying about how others would respond to their different-sex partners. They were not looking for bisexual safe spaces, but for people and organisations that did not embrace or express mononormative assumptions.

Their careers in bisexual organisations had progressed quite steeply: They came into contact with the organisations and then often took up board positions within one year. This shows their determination to become active members of the bisexual movement, as well as the vulnerability of that movement, which was always in need of new board members, as it was difficult to find enough people to run organisations and activities. While the LNBi was originally an association with approximately 200 members, it was difficult to create an active bisexual community (see next section).

This determination and vulnerability alike can also be observed when we look at the key figures' motivations for taking up board positions:

Emiel: What was your motivation to become active?

Harry: Also to do something in return. We found a community in which we felt at home. Next, it was a shame that this community was at risk of collapsing. No activities were organised, and we felt it was important to organise activities. And of course, to meet new people. But also to give people that same spark that we experienced when we first encountered this community. Furthermore, empowerment and recognition. Recognition of the issues you face yourself. And then meeting all kinds of people who have the same things, and you're alike. Yeah, that is really nice. Also people who are shy when first visiting a BiCon and flourish during that conference and dare to interact with other people.

This participant reflects upon his motivations for taking up a board position in the LNBi. Two main themes can be identified from this excerpt: (1) empowering and supporting fellow bisexuals, and providing a space to socialise; and (2) ensuring the continuity of the Dutch bisexual movement. To start with the first theme, all the participants had been looking for a 
space to meet other bisexual people, and had found a (temporary) home for themselves. They wanted to create a home for other bisexual people, not necessarily to help people but to empower them and provide opportunities to socialise (see Bowes-Catton et al., 2011; Toft \& Yip, 2018; Voss, Browne, \& Gupta, 2014). Harry's words are telling: it was really valuable for him to see a shy person visiting an activity such as Holland BiCon and finding the strength and courage to start approaching and socialising with other visitors. As another interviewee, Kate, noted, while the activities of the bisexual movement might seem small and sometimes even insignificant, they meant a lot to bisexual people in the Netherlands, who felt empowered by participating in activities and events.

Second, the excerpt shows that Harry decided to step in because the bisexual community he had found was at risk of collapsing. This was after the LNBi had organised the first EuroBiCon in 2001. The majority of the board members had played key roles in organising this conference, alongside organising regular activities for LNBi members, as well as running their own professional and private lives. Two other participants also mentioned the possible collapse of the bisexual movement as the reason for them stepping up and taking on a board position. One of these, Ingrid, reflected on this negative motivation and argued that it had put all the responsibility on her and the others who had stepped in, contributing to the vulnerability of the Dutch bisexual movement: "If I don't do it, nobody does it, so let's do it. And that is a, how to say, the reality for many volunteers in the bisexual movement. And this motivation is energy-consuming".

A third theme behind stepping up and becoming active was the desire to increase the visibility of bisexuality - within LGBT+ organisations, in the social domain, but also in society as a whole. This motivation was only mentioned explicitly by one participant, but it lay behind in many of the activities and actions instigated by bisexual activists. Remarkably, no participant discussed explicitly political motives, such as civil rights activism to change legislation or policies, as a reason to participate in the Dutch bisexual movement.

\section{Bisexual movement as manifold communities?}

\section{Size and waves}

Ross and colleagues (2018) conclude that bisexual support groups or communities are a rarity. Nevertheless, in the United Kingdom, studies have found that bisexual communities exist and can play an important role in the lives of bisexual people. When asked to describe the bisexual movement or community in the Netherlands, participants mainly reflected on the LNBi.

Participants described the LNBi as a small organisation (200 members) with about 15 active members. These were the board members and a few others who organised activities and ensured the continuity of the association. 
They got help from a few others, who would lend a hand at events organised by the active group or help to organise smaller events. The board was not only responsible for drafting policies and governing the organisation; its members were also the people who actually did the "dirty work". The situation in local organisations was the same.

The Dutch bisexual movement was based on do-it-yourself (DIY) activism, in both national and local bisexual organisations. None of the participants spoke about activists being employed by an organisation; unlike in gay and lesbian organisations, all the work was done by volunteers:

Emiel: Regarding the bisexual community, could you please elaborate on that community in the days when you were involved with it? I mean, when you were an active member?

Mike: We had a group of several dozen people. Some were more active than others, people came and went, but in all those years it was a few dozen ... Some would say 'I don't want to take part in a board or be explicitly labelled as volunteer, but if you need me you can always approach me. Just give me a call and I could possibly organise a workshop'. So these things are interesting for an annual event such as an Autumn Party or a BiVak [naturist camping weekend], or specific events where they want to contribute and not only fool around.

Mike had been active for over ten years in various roles, mostly in board positions in the LNBi. He confirmed the view that the bisexual community or movement consisted of a small group of active members and a small number of others who could be approached to give a workshop, cook at a camping weekend, or help to organise a small event. What is even more interesting is the dynamic he describes in this extract: people come and go. Other participants also reported that people would participate in a bisexual community (often as visitors) for a couple of years, become empowered, and finally leave the bisexual group and stop visiting the activities organised by these organisations. This shows that the bisexual movement did not manage to build a sustainable or even a strong community in people's minds, but often was experienced and used as a (temporary) support group. It is quite likely that these organisations and activities were important to support and empower visitors, but when they felt at ease with their bisexuality, they would stop visiting the events and activities organised by bisexual organisations:

Eveline: I believe I never got a complete view of the bisexual movement. The bi community in the Netherlands is large and diverse. In general people were part of the LNBi [community] for one or two years, they found their home. And after their coming out, you rarely saw them again in the bi group. If I think a bit more, most people were a little bit older, over 30, and they discovered they were attracted to more than one sex or gender. Because they struggled with it, they came to an LNBi event to 
overcome this struggle. A few of them who enjoyed these events stayed and discovered their true selves. They still struggle a bit, but at least still want to be active. So that's always quite a small group of people.

This quotation from Eveline's interview confirms the points made above, but also reveals the difference between the theoretical bisexual community conceptualised as all people who are emotionally and/or sexually attracted to people of more than one sex or gender - and the actual community, which was built around a small group of active people. The time aspect is also interesting: People only participated for one or two years. This observation is not only valid for visitors, but also for volunteers and to a certain extent for the key figures themselves. The key figures were also active for certain (albeit more extensive) periods of time, then left the movement and returned a few years later in different positions.

Returning to Formby (2017), I would argue that the concept of cultural communities is especially applicable to the LNBi and the Dutch bisexual movement. The bisexual activists themselves found a sense of belonging in the LNBi by interacting with other visitors, organisers, and/or activists. In the words of Schatzki (2008), people only coexist - they relate and position themselves in relation to others and the social world - by engaging in shared practices (see also Maliepaard, 2017). Nevertheless, due to its small size, the national bisexual movement easily became a set of personal communities: Most of the key activists really got to know each other and became friends (or acquaintances after leaving the LNBi, as most of them now lived in different areas of the country, or even abroad). In contrast, local organisations often started from personal communities, then contributed to more intense and extended personal communities by organising circles (see below). For instance, Ernst revealed that his participation in a local circle resulted in long-lasting friendships with other bisexual people, even after people had moved to various other parts of the country.

\section{Activities}

The LNBi organised a wide variety of activities, such as the annual Spring Party, the annual Autumn Party, (naturist) camping weekends, coming-out weekends for people who were struggling with their bisexuality, weekends for bi men, lectures on bi-specific topics, workshops to educate others about bisexuality, a quarterly magazine, the annual Holland BiCon (2009-2015), and two EuroBiCons (2001, 2016). Most of these activities were primarily meant to empower other bisexuals, and only secondarily to create a (temporary) bisexual community.

In light of the size of the bisexual movement (or bisexual communities), it may be no surprise that most activities were organised by LNBi board members. As Kate concluded: 
Yes, the board was very much an organising board. I would be delighted with a new bisexual movement in which the board would mainly manage special committees. A board who do not organise activities themselves but who, from a distance, manage the organising committees.

As the LNBi was a small organisation, and the board members organised at least the majority of activities and events, little attention was paid to political issues such as the representation of bisexuality in political domains:

Emiel: So I don't hear much about the political element of bi activism. Was that less of a priority?

Eveline: No, but we mainly focused on COC, we were quite critical of them ... Yes, and also because COC was the main partner of the ministry. The LNBi, together with a few other organisations, were really the smaller ones, so we did not have much to say. It was of vital importance to have COC on our side. So that really was a political objective of the LNBi.

As Eveline argued, the LNBi and other LGBT organisations in the Netherlands were quite small in size, and were not listened to by the government or other institutions. It was important to create awareness among people working at COC (which originally stood for Cultuur en Ontspanningscentrum, or the Center for Culture and Leisure) - the oldest and most professionalised LGBT organisation in the Netherlands - because bisexuality was often neglected and sometimes even erased by this organisation in favour of the normalisation of homosexuality (Van Alphen, 2017) and a politics of difference (cf. Turai, 2018 on the tensions between bisexual people and Hungarian LGBT organisations). One important milestone, according to the activists, is the fact that bisexual people are now explicitly mentioned in COC's statutes as a target group alongside gay men and lesbians.

Later on, this political representation of the LNBi and lobbying for bispecific issues became a true priority, as the LNBi shifted from an association (i.e. a membership organisation) to a foundation (without members). This change meant that the LNBi became more of a lobbying organisation that in theory would represent all bisexual people, rather than only its roughly 200 members. This was a wish come true for several participants, who had felt the pressure to keep organising activities for members who were often critical of the organisation but did not organise events themselves.

Dependency on just a few people means that priorities can be set on the basis of the personal preferences, principles, and convictions of these active members, and can easily shift as the active membership changes (see also Calvo \& Trujillo, 2011; Ferreira, 2014). Furthermore, it also means that it is impossible to initiate and continue activities for different target groups and purposes. For instance, the prioritisation of political representation 
and lobbying resulted in a shift from the organisation of community events towards a greater presence at national and local LGBT gatherings. This change resulted in a decline in events that might potentially contribute to community-building and the direct empowerment of bisexual individuals.

Local organisations mainly organised monthly meetings with the aims of socialisation with other bisexual people and mutual empowerment. Two types of organisations can be identified. On one hand, some organisations held monthly meet-ups that were open to all, in ordinary or LGBT bars or in LGBT venues; on the other hand, some groups or "circles" had memberships, and people had to apply to join. Each member of a circle was supposed to host one of these monthly meetings in their private home. Some circles were exclusively for men or women, some were open to all bisexual people irrespective of gender, and one or two were only for youngsters. An exception to this rule was Gobi, an organisation based in Nijmegen, which not only had circles for bisexual men only, women only, and mixed circles, but was also famous nationwide for its annual Autumn Party (Herfstfeesten), which attracted people from all over the country. These Autumn Parties were held in the local LGBT venue and were meant to celebrate being bisexual. It is safe to conclude that all these activities were the results of DIY activism.

\section{Norms and values}

As Monro (2015) argues, the organised bisexual communities in the United Kingdom probably had much more overlap with kink, BDSM, swingers, or polycommunities compared with mainstream lesbian and gay communities (see also Barker et al., 2012). My study confirms Monro's conclusion, and shows that BDSM and polyamory in particular were understood to be closer to the bisexual movement compared with lesbian and gay organisations. This was not only because at certain times a substantial proportion of the LNBi's board members were into BDSM, polyamory, and/ or swinging themselves, but also because these scenes or interests were part of the workshops and other activities that constituted the Holland BiCons and other events:

Linda: So we started the Gobi Autumn Parties. I managed to lobby COC this party was held at the COC venue - to have a true [mixed-gender] darkroom. I was part of a COC discussion group as a representative of Gobi, and these people were like, 'Yeah, really? Those bisexuals want a darkroom ... that will be a total failure'. ... So about one and a half months later we met again, and they were really eager to learn about the darkroom. I was like, 'You don't want to know, it was crowded! People had to wait at the entrance [of the darkroom]'. They were like, 'Are you kidding?' Then I explained that such a darkroom meets some demands of bisexual people, and these people need to decide for themselves whether they will participate in it or not, and to what extent. 
Linda had been very active in a local organisation - for instance, setting up new circles and coordinating activities. The extract above from her interview reflects sex positivity and a laissez-faire attitude to sexuality (see also Chapter 11 in this book): sex should have a place at events, and visitors should be able to choose for themselves whether to participate in more sexualised activities. As the extract reveals, it was a big success, and people had to queue outside the mixed-gender darkroom due to its popularity. Participants also spoke about workshop topics such as BDSM for beginners or ethical polyamory as examples of the interwovenness of bisexuality and other sexual and romantic preferences.

Key activists wanted to be inclusive of all kinds of bisexual people, and to create practices that celebrated diversity among bisexual people:

Mike: We always explicitly mentioned in our oral and written communications that bisexual people exist in many different ways. They all are perfect. They can be monogamous and choose one partner for the rest of their lives. They can be poly and have multiple relationships with men, women, and couples. They can also be part of all kinds of different scenes. Everything is possible. A number of bisexual people did not really agree with that, because they experienced it like we wanted to impose norms and values on them. Some possibly experienced that one type would become dominant over others. We always stressed that this was not the case: everyone is equal.

Mike and other LNBi board members stressed inclusivity in their internal and external communications, and in the activities they organised. They purposefully tried over the years to create a habitus (norms, values, activities, actions) that would be inclusive of, and understood and accepted by all bisexual people. As Mike said, his experience was that not all bisexual people took these norms, values, and activities for granted. A number of bisexual people experienced the activities as imposing a particular habitus, and sometimes even contested them because they were scared that one type of bisexuality would become dominant in the practices of the LNBi.

A number of monogamous bisexual people did not feel at ease with the explicit attention to (bi)sexual desire and sex, as they felt this might strengthen stereotypes of bisexual people as promiscuous or hypersexual. Further, as other activists argued, the openness towards non-monogamous sexual practices during these events - and sometimes also afterwards (e.g. if visitors to a BiCon stayed over at an organiser's home to participate in sex parties) - could be an overwhelming experience for newcomers to the bisexual movement or visitors to events. Another key activist, Ernst, suggested that some bisexual people did not join the LNBi's camping weekends because they were naturist events. In other words, not relating to the habitus could result in people ceasing to participate in particular activities, and perhaps in their ceasing to visit activities organised by bisexual organisations altogether. 
Reflecting on the evolution of LGBT activism in Spain, Calvo and Trujillo (2011) argue that more conformist or state-oriented LGBT organisations focused on normalisation and love rights (family rights, such as equal marriage), whereas more revolutionary or underground organisations focused on sex rights and sex(uality). Fillieule and Duyvendak (1999) similarly conclude that the "older" and state-oriented gay and lesbian movement in France was more focused on equal treatment and equal rights, instead of campaigning for extra or special treatment. (See also Ferreira, 2014 and Van Alphen 2017 for similar observations on activism in Portugal and the Netherlands respectively.) While the LNBi shifted from a more communityfocused organisation to a more politically oriented organisation, its attention to sex and sexuality did not fade away, and seemed to be relatively firmly grounded in the organisation's activities, norms, and values.

Most participants experienced a space where they could be different and be their true selves. This was not limited to norms and values related to sexuality or relationship diversity. One participant, Chris, discussed the acceptance of people living with autistic spectrum disorder, who in his experience were widely present in the bisexual movement (and the gay and lesbian movement). The emphasis on mutual care, respect, and the empowerment of others was identified as a key value of the bisexual movement. This is no surprise in light of the activists' aforementioned motivations for taking up key positions in local and national organisations, and the nature of activities such as circles, coming-out weekends, camping activities, and so on. It is also no surprise that bisexual people should interpret bisexual organisations as support groups for people who are struggling with their bisexuality (Maliepaard, 2017; Toft \& Yip, 2018).

Finally, for a number of people, the emphasis on empowering other bisexuals also meant a shift away from presenting bisexuals as victims of the mononormative system, lesbian and gay organisations, and others who contributed to the double stigmatisation of bisexual people. At times, they argued, bisexual organisations focused too much on the problems bisexual people may have had in their daily lives, and not enough on the positive sides of bisexuality. As Harry put it:

I don't know, but when I became part of the bi community, I felt they only talked about problems ... So I really challenged this way of presenting bisexuality. Immediately playing the victim card.

As Gusmano (2017) suggests, it is important for LGBT organisations to acknowledge that the discourse of victimisation and discrimination can obscure the "positive self". Not only Harry, but also Linda and Eveline, emphasised that they felt it was easier to empower other bisexuals by using a positive approach and embracing the positive self: "We are proudly and happily bisexual! Let's celebrate it!" As Linda said of people who applied for 
membership of a bisexual circle, "Is it a happy bisexual or a sad one? No, we have sad one again. Let's make them a happy bisexual!"

\section{Reflections and recommendations}

The above sections draw a picture of a small bisexual movement, consisting of approximately ten to 15 people at the national level, and similarly small groups/communities at the local level, constituting a small core team, with a group of people that could be approached for minor organisational tasks or to give workshops. At the national level, it becomes clear that the LNBi mainly organised activities for its own members until approximately December 2011, when it became a foundation and prioritised bisexual representation within the wider LGBT movement, government institutions, and research institutes. Because of the LNBi's limited capacity, its board members constantly needed to choose their priorities and were at risk of exhaustion. It is no surprise that the LNBi witnessed a number of crises - for instance, after organising energy-consuming events such as the EuroBiCons in Rotterdam (2011) and Amsterdam (2016). New activists had to step into an organisation that was already exhausted. It is quite telling that most participants mentioned self-care as their main tip for the new(er) generation(s) of bi activists.

While bisexual organisations in Germany and the United Kingdom seem to have been successful at the national and local levels (EuroBiCon, 2020), this does not apply to bisexual organisations in every European country, as work on Finland (e.g. Lahti, 2019) and Hungary (Turai, 2018) has shown. In the Netherlands, the LNBi announced its dissolution in 2019 after more than 25 years of activism, community-building, and bisexual representation. It is difficult to assess the impact of the LNBi; however, if we look at people's personal reasons for becoming active in the bisexual movement, it is possible to draw tentative conclusions. These reasons were (1) to empower and support fellow bisexuals, and provide a space for socialising; (2) to ensure the continuity of the Dutch bisexual movement; and (3) to create bivisibility.

To start with the first of these, the LNBi and local organisations contributed to community-building (i.e. fostering personal communities), but above all to empowering and supporting bisexual people by organising activities such as coming-out weekends, camping weekends, BiCon, and local gatherings (the aforementioned circles). While these activities may seem mundane, they contributed to the empowerment of bisexual people, and helped people to explore and accept their bisexuality and sometimes also other aspects of their lives. The majority of participants gave examples of "sad bisexuals" (i.e. bisexual people who struggled with their sexuality or socially) that turned into "happy bisexuals" by participating in activities at national and local levels. It should be said, however, that despite the attempts of key activists and others to create a particular habitus that would be inclusive of 
all kinds of bisexual people, members of the LNBi sometimes contested the "imposed" habitus, and were scared that one type of bisexuality or bisexual people would become dominant in the LNBi and its activities.

Second, participants succeeded in keeping the LNBi alive for over 25 years, and other local organisations also had extended lifespans thanks to the efforts of bisexual activists. Nevertheless, as I observed in the introduction, the bi landscape nowadays is impoverished. At the time of writing in 2019, only four cities have monthly meetings, and the organisers regard these meetings as only partially successful. In late summer 2019, a new national organisation was founded: $\mathrm{Bi}+$ Nederland (Bi+ Netherlands). The founders of this organisation all met through activities instigated by the LNBi, in particular the EuroBiCon of 2016.

Third, participants contributed to TV shows, radio interviews, and newspaper articles, and created awareness of bisexuality in LGBT organisations and Dutch national and local politics. While most local organisations and the LNBi no longer exist, this does not mean that individual activists have stopped their efforts to make bisexuality more visible in everyday life; however, this is now more incidental than before, and takes place via social media more often than through other channels.

\section{Recommendations}

While conducting this study, I also asked the key activists whether they had any suggestions for the "new" generation of bi activists, and we discussed at length the development (including the highs and lows) of the Dutch bisexual movement. On this basis, I offer three recommendations for existing and future organisations that want to represent plurisexual people and/or create new communities:

1. Organisations need to strike a balance between the political representation of bisexuality and activities for plurisexual people. Representation and lobbying are important; however, bisexual and other plurisexual people should be the main focus of these organisations. The empowerment of and support for bisexual people have been a focus in the past and have meant a lot to plurisexual people. Having a visible and strong community will also help political representation and lobbying activities.

2. Organisations need to professionalise and strengthen their human resources. Currently, organisations depend on a few individuals or small personal communities of activists. To ensure the continuity of organisations/activities and the wellbeing of activists/volunteers, organisations need to increase their numbers of structural volunteers.

3. Boards of organisations need to have a clear and positive vision and objectives, which should take the lead; personal objectives and interests need to be subordinate. This may prevent crises on boards, and ensure that more volunteers will lead the organisation together and share 
their responsibilities, instead of putting pressure on one or a few board members. The vision should embrace the "happy bisexual" (the positive self) instead of emphasising the marginalisation of bisexuality and bisexual people.

\section{References}

Anderson, B. (2006). Imagined communities: Reflections on the origin and spread of nationalism. London: Verso.

Atkinson, R. (2002). The life story interview. In J.F. Gebrium, \& J.A. Holstein (Eds.), Handbook of interview research: Context \& method (pp. 121-40). London: Sage.

Barker, M.J., Richards, C., Jones, R., Bowes-Catton, H., Plowman, T., Yockney, J. \& Morgan, M. (2012). The bisexuality report: Bisexual inclusion in LGBT equality and diversity. Maidenhead: The Open University. Retrieved from www. bisexualindex.org.uk/uploads/Main/TheBisexualityReport.pdf

Bowes-Catton, H., Barker, M.J., \& Richards, C. (2011). 'I didn't know that I could feel this relaxed in my body': Using visual methods to research bisexual people's embodied experiences of identity and space. In P. Reavey (Ed.), Visual methods in psychology (pp. 255-70). London: Routledge.

Calvo, K., \& Trujillo, G. (2011). Fighting for love rights: Claims and strategies of the LGBT movement in Spain. Sexualities, 14(5), 562-79. doi: 10.1177/ 1363460711415330

Eadie, J. (1993). Activating bisexuality: Towards a bi/sexual politics. In J. Bristow \& A.R. Wilson (Eds.), Activating theory: Lesbian, gay, bisexual politics (pp. 31-46). London: Lawrence \& Wishart.

EuroBiCon (2020). Bisexual guide to Europe. Retrieved from www.eurobicon.org/ bisexual-guide-to-europe

Ferreira, E. (2014). Lesbian activism in Portugal. Lambda Nordica, 19(2), 53-82.

Fillieule, O., \& Duyvendak, J. (1999). Gay and lesbian activism in France between integration and community-oriented movements. In B. Adam, J. Duyvendak \& A. Krouwel (Eds.), The global emergence of gay and lesbian politics: National imprints of a worldwide movement (pp. 184-213). Philadelphia, PA: Temple University Press.

Formby, E. (2017). Exploring LGBT spaces and communities: Contrasting identities, belongings, and wellbeing. London: Routledge.

Gusmano, B. (2017). Uncomfortable bargains? Networking between local authorities and LGBT associations in the context of neoliberalism. In A. King, A.C. Santos, $\&$ I. Crowhurst (Eds.), Sexualities research: Critical interjections, diverse methodologies, and practical applications (pp. 153-66). New York: Routledge.

Hemmings, C. (2002). Bisexual spaces: A geography of gender and sexuality. London: Routledge.

Lahti, A. (2019). Bisexuality in relationships: A queer psychosocial approach. Jyväskylä: University of Jyväskylä.

Maliepaard, E. (2017). Bisexuality in the Netherlands: Connecting bisexual passing, communities, and identities. Journal of Bisexuality, 17(3), 325-48. doi: 10.1080/ 15299716.2017.1342214

Maliepaard, E. (2019). De bi-beweging in Nederland: Ontwikkelingen en ervaringen van vooraanstaande bi-activisten sinds de jaren '90 [The bisexual movement in 
the Netherlands: On developments and on experiences of key bi-activists since the early 1990]. Retrieved from https://s3-eu-central-1.amazonaws.com/atria-nl/ wp-content/uploads/2019/09/05095741/Maliepaard-2019-De-bi-beweging-inNederland-definitieve-onderzoeksrapportage.pdf

Maliepaard, E. (2020). Spaces with a bisexual appearance: Reconceptualizing bisexual space(s) through a study of bisexual practices in the Netherlands. Social and Cultural Geography, 21(1), 45-63. doi: 10.1080/14649365.2018.1454979

Monro, S. (2015). Bisexuality: Identities, politics, and theories. Basingstoke: Palgrave Macmillan. doi: 10.1057/9781137007315

Ross, L.E., Salway, T., Tarasoff, L.A., MacKay, J.M., Hawkins, B.W., \& Fehr, C.P. (2018). Prevalence of depression and anxiety among bisexual people compared to gay, lesbian, and heterosexual individuals: A systematic review and meta-analysis. The Journal of Sex Research, 55(4-5), 435-56. doi: 10.1080/ 00224499.2017.1387755

Schatzki, T.R. (2008). Social practices: A Wittgensteinian approach to human activity and the social (2nd ed.). Cambridge: Cambridge University Press.

Toft, A., \& Yip, A.K.T. (2018). Intimacy negotiated: The management of relationships and the construction of personal communities in the lives of bisexual women and men. Sexualities, 21(1-2), 233-50. doi: 10.1177/1363460716679793

Turai, R.K. (2018). Gender and class tensions in Hungarian LGBTQ activism: The case of ambiguous bisexual representation. In R. Buyantueva, \& M. Shevtsova (Eds.), LGBTQ+ activism in Central and Eastern Europe: Resistance, representation and identity (pp. 341-68). Cham: Springer. doi: 10.1007/978-3-030-204013_14

Van Alphen, E.C.J. (2017). Erasing bisexual identity: The visibility and invisibility of bisexuality as a sexual identity in the Dutch homosexual movement, 1946-1972. Journal of Homosexuality, 64(2), 273-88. doi: 10.1080/00918369.2016.1179032

Van Lisdonk, J. \& Keuzenkamp, S. (2017). Towards bi-inclusive policies: Suggestions based on research on Dutch same-sex attracted young people. Sexuality Research and Social Policy, 14(2), 206-22. doi: 10.1007/s13178-016-0241-1

Voss, G., Browne, K., \& Gupta, C. (2014). Embracing the "and": Between queer and bisexual theory at Brighton BiFest. Journal of Homosexuality, 61(11), 1605-25. doi: 10.1080/00918369.2014.944055 